\title{
A ontologia do ato de avaliar
}

\author{
João Batista Zanardini*
}

\section{Resumo}

Este artigo problematiza os resultados educacionais apresentados quer por instrumentos nacionais de avaliação, quer por internacionais, os quais remetem a um suposto anacronismo da escola. De forma agregada à publicização desses resultados vem à tona a afirmação acerca da ineficiência da escola em garantir condiçóes satisfatórias de ensino e aprendizagem dos conteúdos, atitudes e habilidades tidas como necessárias ao bom funcionamento da sociedade. $\mathrm{O}$ artigo retoma os pressupostos ontológicos que embasam este processo de "mudança na permanência" que engloba as reformas do aparelho do Estado, com a imposição do Estado avaliador, e o recrudescimento da relevância dos mecanismos de avaliaçáo educacional em larga escala, sobretudo a partir de 1990. Discute os pressupostos ontológicos do processo de avaliação como constituintes do trabalho, bem como a caracterização ontológica atribuída a estes processos pela classe dominante, concluindo que se tratam de caracterizaçóes de intencionalidades distintas, partem de projetos sociais distintos, e, portanto, têm em vista modelos de homem distintos.

Palavras-chave: Avaliação educacional. Educação Básica brasileira. Ontologia.

* Doutor em Educação pela Universidade Federal de Santa Catarina. Professor do Curso de Pedagogia da Universidade Estadual do Oeste do Paraná - Campus Cascavel, PR. 


\section{Introdução}

Os problemas educacionais, ou o baixo rendimento dos alunos em testes avaliativos de larga escala servem muitas vezes de justificativa para os problemas sociais, como por exemplo, a pobreza e condições de miserabilidade de várias formas que figuram como marca indelével da sociabilidade regida pelo capital. Desse modo, a educação que se propaga como a ideal, se mostra como uma imprescindível forma de ajuste das desigualdades sociais. Trata-se da educação eficiente, capaz de reverter os baixos escores dos estudantes nos testes avaliativos, dotando-os de habilidades e competências requeridas pela sociabilidade assentada no lucro e acenar como possibilidade de saída de uma condição econômica desfavorável, a pobreza, por meio do empoderamento dos mais pobres, tornando-os assim, pobres eficientes.

A eficiência dita o tom das açóes do Estado capitalista na avaliação e no controle social, impondo como norma para a educação a transposição do escrutínio da eficiência, que deve ser constantemente avaliada e rotulada pelos seus resultados. Para tanto, muitos aspectos que interferem no aprendizado por parte dos estudantes são desconsiderados, recebendo atençáo maior o rendimento dos alunos em testes ou provas que intentam mensurar seus conhecimentos.

Considerando que a avaliação só tem razão de existir, se estiver ontologicamente fundamentada num projeto social mais amplo, posicionada de forma a obter respostas significativas para este projeto social, é que nos reportamos à avaliação do rendimento escolar nos seus aspectos ontológicos que a formatam dessa, ou daquela maneira.

Antes de adentrarmos na discussão dos aspectos ontológicos da avaliação do rendimento escolar conceituemos o que denominamos como ato avaliativo, pois compreendemos que tal conceituação permitirá diferenciar a avaliação de um mero processo de verificação. Tracemos, em linhas gerais, uma definição de avaliação, ${ }^{1}$ conscientes da dificuldade, e até mesmo da impossibilidade, de defini-la de uma vez por todas. Saul (1994, p. 95) sugere que, "[...] quando falamos em avaliação, não estamos sempre nos referindo à mesma coisa. Já houve quem dissesse que avaliação é um 'casaco de várias cores', indicando assim que, apesar de ter a mesma raiz, a mesma essência, a avaliação tem muitos ramos, muitas dimensóes”. 
Sabendo dessa dificuldade procuramos estabelecer uma definição tratando da avaliação de forma mais geral, ${ }^{2}$ pois, sendo a avaliação escolar uma prática avaliativa, a mesma, apesar de formada por matizes que lhe são próprios, terá seu rigor conceitual respaldado nesta definição mais ampla. $\mathrm{O}$ termo avaliar tem sua origem na língua latina, na composição $a$-valere que significa "valorar a...", ou seja, "dar valor a...". Podemos afirmar que esse conceito é formulado tendo por base as determinaçóes do comportamento de atribuir valor, ou qualidade, a alguma coisa, realização ou decorrer de uma ação que, por si só, admite um posicionamento que nega ou reforça positivamente o objeto ou, como dissemos, a coisa, a realização ou o decorrer da ação avaliada. De acordo com Luckesi (1995, p. 93):

$\mathrm{O}$ ato de avaliar implica coleta, análise e síntese dos dados que configuram o objeto da avaliação, acrescido de uma atribuição de valor ou qualidade, que processa a partir da comparação da configuração do objeto avaliado com um determinado padrão de qualidade previamente estabelecido para aquele tipo de objeto. $\mathrm{O}$ valor ou qualidade atribuído ao objeto conduzem a uma tomada de posição a seu favor ou contra ele. E o posicionamento a favor ou contra o objeto, ato ou curso da ação, a partir do valor ou qualidade atribuído, conduz a uma decisão nova: manter o objeto como está ou atuar sobre ele.

Sendo assim, a avaliação pode ser definida como ajuizamento ${ }^{3}$ da qualidade da coisa ou da ação avaliada, logo, implica um posicionamento com relação ao que se avalia, podendo refletir na sua aceitação ou transformação. Luckesi (1995, p. 33) define avaliação como “[...] um julgamento de valor sobre manifestações relevantes da realidade, tendo em vista uma tomada de decisão". Considerar a avaliação como um juízo de valor significa perceber que encerra uma afirmação qualitativa sobre determinada coisa ou ação, sempre com base em critérios preestabelecidos. Ou seja, o que se avalia será tanto mais satisfatório quanto menos se distanciar do ideal preestabelecido. Esse juízo de valor se realiza com base nas características relevantes do objeto da avaliação, portanto, "O juízo emergirá dos indicadores da realidade que delimitam a qualidade efetivamente esperada do objeto. São os sinais do objeto que eliciam o juízo. E, evidentemente, a seleção dos sinais que 
fundamentarão o juízo de valor dependerá da finalidade a que se destina o objeto a ser avaliado" (LUCKESI, 1995, p. 33).

A avaliaçáo necessariamente conduz a um posicionamento frente à porçấo do real que se toma para objeto de exame. Ou seja, o juízo de valor, pela sua especificidade mesma, como processo humano, portanto social, se reflete ${ }^{4}$ num posicionamento de não indiferença, o que significa obrigatoriamente um posicionamento e conseqüentemente uma decisão frente ao que se avalia. Nesse caso, recai-se em três possibilidades de decisão: deixar, ou agir de forma que se mantenha a situação, o objeto ou a ação, introduzir modificaçóes para que o objeto avaliado se modifique positivamente ou suprimir a situação, a ação ou o objeto. ${ }^{5}$ De acordo com o exposto, o processo avaliativo engloba os aspectos referentes ao julgamento e também à tomada de decisão, justamente por diferenciar-se da mera verificaçâao. ${ }^{6}$ Esta última é entendida como ação que "congela" o objeto, pois se encerra no momento em que se chega à conclusão de que o objeto, a coisa ou a situação possui determinada configuração. Luckesi (1995, p. 92) afirma que "A dinâmica do ato de verificar encerra-se com a obtenção do dado ou informação que se busca, isto é, 'vê-se' ou 'não se về alguma coisa. E... pronto! Por si, a verificaçáo não implica que o sujeito retire dela conseqüências novas e significativas."

Sendo assim, há uma diferenciação qualitativa referente à finalidade de ambos os processos - de avaliaçáo ou de verificação - que pode ser apreendida pelo fato de emular transformaçôes positivas ou negativas no objeto, na açáo ou principalmente no sujeito avaliado. Essa particularidade, fundamental, relativiza o fato de ser a avaliação uma prática realizada por um sujeito, ou por sujeitos, pois tanto uma como a outra se constituem como um empreendimento eminentemente social, por isso mesmo têm reflexos sociais que escapam ao âmbito da avaliaçáo tomada de forma individualizada. Logo, as consideraçóes que dizem respeito a avaliação tomada no seu aspecto mais geral são válidas também para o caso específico da avaliação educacional, pois as tomamos em seu aspecto reflexivo diante daquilo que se propóem a avaliar. Tanto num caso quanto no outro o processo de avaliação terá reflexo na prática social dos sujeitos envolvidos, e é este aspecto que nos interessa.

Dito de outro modo, mesmo um processo de avaliaçáo externa, ${ }^{7}$ como é o caso do levado a cabo pelos instrumentos avaliativos educacionais, reflete-se na prática dos sujeitos avaliados e esse reflexo pode atuar numa 
perspectiva de mudança qualitativa ou numa perspectiva de manutenção do quadro que supostamente se avalia. Logo, o diferencial que caracteriza um ato avaliativo ou de mera verificação é percebido pelo seu resultado na práxis, evidenciando uma mudança qualitativa, no primeiro caso, ou a manutenção, no segundo.

Desse modo, quando analisamos os resultados escolares difundidos pelos instrumentos avaliativos de larga escala da Educação Básica, principalmente a partir da década de 1990, quer sejam nacionais ou internacionais, dos quais são exemplos o Sistema Nacional de Avaliação da Educação Básica (SAEB), o Exame Nacional do Ensino Médio (ENEM) e o Programa Internacional de Avaliação de Estudantes (PISA), o fazemos tendo em vista captar o reflexo que têm na prática educativa dos sujeitos que são avaliados, alunos e professores. Tal reflexo se dá de acordo com a função social desses testes. De acordo com Nagel (1996, p. 29):

A avaliação só tem função social quando está intimamente vinculada a um projeto de vida para os homens. Educa-se, ensina-se, para a sociedade que se deseja ver transformada (ou náo). Se não existe projeto de vida para os homens obterem o que ainda não foi alcançado, não há necessidade social de avaliação a náo ser a de preencher com notas os boletins curriculares individuais. A avaliação em si mesma, tomada como operação técnica, não tem sentido, nem significado. A avaliaçáo tem - enquanto técnica - a função de prover informaçôes úteis aos homens. E é nos limites dessa possibilidade técnica de prover informaçôes úteis, importantes, necessárias aos homens, que a questão básica se impóe: o que é útil, importante e necessário para os homens?

O que caracteriza a função social dos processos avaliativos em larga escala é a mera verificação com ênfase na cobrança e culpabilização dos envolvidos com as unidades escolares, sejam eles gestores, professores, funcionários, pais, alunos ou comunidade, em relação à qualidade e eficiência da educação escolar. Nessa suposta perspectiva de avaliação, o controle dos processos baseado na supervisão direta é substituído por estratégias que não ultrapassam a aferição e a comparação de resultados, 
o qual não contempla outros elementos determinantes que incidem nos resultados escolares.

Quando analisamos os resultados educacionais apresentados quer por instrumentos nacionais de avaliação, como SAEB e ENEM, quer por internacionais, caso do PISA, somos remetidos ao suposto problema do anacronismo da escola. Ou seja, de forma agregada à publicização dos resultados dos rendimentos escolares, vem à tona a afirmação acerca da ineficiência da escola em garantir condições satisfatórias de ensino e aprendizagem dos conteúdos, atitudes e habilidades tidas como necessárias ao bom funcionamento da sociedade.

A educação escolar nacional, particularmente a Educação Básica, sobretudo a partir da década de 1990 , vem sendo objeto de reformulaçóes como a realizada no âmbito do currículo. Com a implementação dos Parâmetros Curriculares Nacionais, que postulam entre seus objetivos justamente a solução do problema do anacronismo educacional, propunhase suplantar os conteúdos ultrapassados e obsoletos que a escola transmitia posto que ancorados em uma política educacional avaliada como inadequada.

Além da reforma no âmbito do currículo, com a promulgação da Lei no 9394/96, Lei de Diretrizes e Bases da Educação Nacional (BRASIL, 1996), intensificou-se um amplo processo de avaliação do sistema escolar em todos os seus níveis e promoveu-se uma política de ajuste das universidades públicas. Foi instituído também um fundo de recursos para a valorização do magistério, o FUNDEF. ${ }^{8} \mathrm{Ou}$ seja, no âmbito das políticas educacionais as reformas dos anos de 1990 foram propostas com base na afirmação de um problema educacional, para o qual urgia uma solução. Pensemos um momento dessa forma e chegaremos a uma aparente contradição: apesar da "ampla reforma curricular" levada a cabo com a implementação dos PCN, e todo o quadro de reformas educacionais apresentadas como corolário do processo de reforma do Estado na década de 1990, a Educação Básica nacional, segundo os resultados dos exames SAEB, ENEM e PISA, não logrou alcançar um escore satisfatório nos instrumentos de avaliação. Para analisar tal situação é necessário entender os pressupostos ontológicos que embasam este processo de "mudança na permanência" que engloba as reformas do aparelho do Estado, com a imposição do Estado avaliador, e o recrudescimento da relevância atribuída aos mecanismos de avaliação educacional em larga escala. 
Para refletirmos sobre a aparente contradição apontada consideramos de fundamental relevância discutir os pressupostos ontológicos do processo de avaliação como constituintes do trabalho, bem como a caracterização ontológica atribuída a estes processos pela classe dominante. São caracterizaçóes de intencionalidades distintas, partem de projetos sociais distintos, têm em vista modelos de homem distintos. A avaliação consubstanciada no trabalho carrega em si uma positividade que necessariamente resulta numa mudança qualitativa na práxis social, impulsionando os homens à frente; a avaliação levada ao cabo pelas classes dominantes, diretamente ligada à manutenção da sociabilidade baseada na desigualdade de classes, intenta a conservação da dominação do homem pelo homem, por mais que, entre seus argumentos ideológicos, propague um ajuste social via educação.

\section{Considerações a respeito da ontologia do ato de avaliar}

O que estamos tomando neste trabalho por ontologia do processo avaliativo significa aquilo que o constitui como tal, ou seja, o que caracteriza o seu ser em si. Sendo assim, ao longo da história o processo avaliativo sofreu modificações e sua caracterização e constituição depende e é determinada pelos interesses a que esteve ligado, como afirma Moraes (2000, p. 20), "[...] quando se fala em ontologia, o que está em jogo é a tessitura mesma do real."

Ao refletirmos a respeito da forma como o ato de avaliar acompanhou a humanidade ao longo de sua história, ${ }^{9}$ consoante com o modo como os homens organizaram a produção e manutenção de sua vida, o trabalho se mostra como fundamento da avaliação. O processo de avaliação é resultado de complexas mediaçóes cujas raízes brotam do trabalho, logo, pensamos que, no plano ontológico, estas mediaçóes, bem como o ato de avaliar, devem ser entendidas com base no trabalho.

A compreensão de trabalho que permeia nossa análise vem de Marx (1988, p. 142-143) quando afirma:

Pressupomos o trabalho numa forma em que pertence exclusivamente ao homem. Uma aranha executa operaçóes semelhantes às do teceláo, e a abelha envergonha mais de um arquiteto humano com a construção dos favos de suas colméias. Mas o que distingue, de antemão, o pior arquiteto da 
melhor abelha é que ele construiu o favo em sua cabeça, antes de construí-lo em cera. No fim do processo de trabalho obtém-se um resultado que já no início deste existiu na imaginação do trabalhador, e portanto idealmente. Ele não apenas efetua uma transformação da forma da matéria natural; realiza, ao mesmo tempo, na matéria natural seu objetivo, que ele sabe que determina, como lei, a espécie e o modo de sua atividade e ao qual tem de subordinar sua vontade.

Esta forma de analisar a avaliação considera o trabalho como ato fundante do ser social, ato que inaugura a prática social da humanidade, ato que pressupóe uma intencionalidade prévia. Logo, ao analisarmos ontologicamente qualquer uma das características que compóem as demais esferas da práxis social, como é o caso da avaliação, devemos considerar que esta advém do trabalho, tem nele sua gênese ontológica.

A análise ontológica do processo de avaliar se estabelece na medida em que - e por considerá-la nascente no e do trabalho, portanto, indissociável dele - se considera a primazia do trabalho como protoforma da práxis social. A potencialidade desta forma de encarar o processo avaliativo ocorre justamente pela ação crucial que a avaliação exerce, mesmo que ao lado de inúmeras outras mediaçóes, no processo de trabalho na constituição do ser social. A avaliação auxilia o processo de hominizaçáo como parte imprescindível do fazer-se homem do homem, posto que o processo de avaliação nasce com o trabalho, desde o salto que separa o gênero humano e o distingue dos demais animais, o que lhe confere de fato hominidade. Sendo assim, podemos afirmar que, a exemplo do trabalho, a avaliação também é uma atividade exclusivamente humana.

Mesmo reconhecendo a impossibilidade de resgatar as peculiaridades originais do processo avaliativo, ao se estabelecer sua análise respaldada na consideração do trabalho como momento inaugural do ser social é possível garantir aspectos que lhe são constituintes e lhe formatam. Esta ideia auxilia o entendimento do processo avaliativo e a posterior comparaçáo com a avaliação que se realiza sob a égide do capital que possui uma intencionalidade ontologicamente ligada aos interesses da classe que a legitima e a referenda. 
Embora o processo avaliativo como construção social tenha uma dimensão simbólica, o mesmo não deve ser reduzido à sua aparência. Ele tem uma efetividade, uma positividade desde o salto que inaugura o ser social e esta efetividade não pode ser reduzida, a nosso ver, à "casca" que lhe empresta aparência, dado que subjacente a qualquer construção social existe uma ontologia. Há uma distinção entre o que se construiu ontologicamente em torno da avaliaçáo no interior da sociedade capitalista quando comparado com o que ontologicamente a constitui como componente do trabalho. Quando discutimos os resultados avaliativos expressos pelos diferentes instrumentos de avaliação do rendimento escolar objetivamos compreender a conexão existente entre esses resultados apresentados como indesejados e a ontologia conservadora que rege a implementação dessas políticas educacionais.

Intentamos estabelecer um contraponto entre os componentes ontológicos que caracterizam o ato avaliativo como extensão da práxis social desdobrada do trabalho e a ontologia que embasa a avaliação realizada no interior do modo de produção capitalista consubstanciada na ontologia liberal conservadora da classe que detém o poder político-econômico e, por que não dizer, avaliativo. Medeiros (2004, p. 4, grifo do autor) enuncia os três princípios ontológicos que dão substância à visão de mundo conservadora do status quo regido pelo capital:

(1) o princípio da naturalização do capital, que significa o entendimento de que as estruturas sociais existentes são efetivamente imutáveis; (2) o princípio do atomismo social, que caracteriza a sociedade como um objeto constituído por uma simples agregação de indivíduos, e (3) o princípio do proferimento abstrato de valores emancipatórios, que se refere à descrição dos valores como entidades absolutamente subjetivas, descoladas da práxis social.

Ao veicular os resultados educacionais pelos relatórios dos programas avaliativos, como é o caso do SAEB, ENEM e PISA, e relacioná-los a um suposto fracasso da escola a ontologia conservadora que os regulamentou e implementou está justamente amparada no primeiro dos princípios expostos acima, ou seja, na suposta imutabilidade das estruturas sociais vigentes e na conseqüente naturalização do capital. 
Considerando o processo avaliativo como construção especificamente social, ou melhor, do ser social e subsidiando sua relevância ontológica em formas de ser a ele precedentes, bem como sua articulaçáo com estas formas, referimos, em nossa análise, o papel crucial que o trabalho tem nesta constituição. Ou seja, o primeiro empreendimento social é o trabalho e dele advém outras formas sociais que compóem a práxis social que não podem ser hierarquizadas, dentre elas se encontra o ato avaliativo. Sendo a categoria fundante da complexidade das relaçóes sociais, o trabalho tem prioridade ontológica, é modelo da práxis social em geral, ${ }^{10}$ fonte ontologicamente necessária de outras categorias que compóem a práxis social. As categorias das quais a avaliação é um exemplo possuem essencialmente um caráter social, pois se desdobram no ser social constituído. Segundo Lukács (1981, p. 14),

Somente o trabalho tem, como sua essência ontológica, um claro caráter intermediário: ele é, essencialmente, uma inter-relação entre homem (sociedade) e natureza, tanto inorgânica (utensílio, matéria-prima, objeto do trabalho etc.) como orgânica, inter-relação que pode até estar situada em pontos determinados da série a que nos referimos, mas antes de mais nada assinala a passagem, no homem que trabalha, do ser meramente biológico ao ser social.

Seguindo os passos de Lukács (1981), quando afirma que "o homem é um ser que responde", complementamos da seguinte forma: o homem é um ser que responde segundo determinados critérios e é aí, neste ponto, que se encontra a relevância crucial da avaliação que atua como coadjuvante do processo de trabalho em seu aspecto cognitivo. Resguardar o trabalho como categoria ontológica central é, a nosso ver, imprescindível, pois somente por seu intermédio realiza-se, no âmbito do ser material, uma posição teleológica que origina uma objetividade até então inexistente. Pelo trabalho o homem realiza uma posição teleológica com intencionalidade pré-existente cujo resultado é uma nova objetividade. Essa prévia intenção é composta pela apreensáo do reflexo correto da realidade que se pretende transformar via trabalho.

Segundo Lukács (1981, p. 19), 
Assim, o trabalho se torna o modelo de toda práxis social, na qual, com efeito - mesmo que através de mediaçóes às vezes muito complexas - sempre são transformadas em realidade posições, em termos que, em última análise, são materiais. É claro, como veremos mais adiante, que não se deve ser esquemático e exagerar este caráter paradigmático do trabalho em relação ao agir humano em sociedade; mas assim mesmo, ressalvadas as diferenças, que são muito importantes, veremos que há uma essencial afinidade ontológica e esta brota do fato de que o trabalho pode servir de modelo para compreender as outras posiçóes sócio-teleológicas exatamente porque, quanto ao ser, ele é a forma originária.

Se há uma intencionalidade prévia, imbricada nela há uma cognoscibilidade e entrelaçado neste processo complexo encontra-se o ato de avaliar como constituinte do trabalho. Se considerarmos o ocorrido num ato de trabalho primitivo como a escolha de uma dentre tantas outras pedras com vistas a eleger qual se prestaria para uma suposta transformação da natureza, visando a satisfação de uma necessidade humana, segundo exemplo de Lukács (1981), mesmo nesse ato que repousa nos primórdios do estabelecimento do homem como ser social podemos ver o papel relevante do ato avaliativo na apreensão correta do reflexo que desemboca nessa tomada de decisão. Para o autor:

Mediante a observação e a experiência, isto é, mediante o reflexo e a sua elaboração na consciência, devem ser identificadas certas propriedades da pedra que a tornam adequada ou inadequada para a atividade pretendida. Quando olhado do exterior, este ato extremamente simples e unitário que é a escolha de uma pedra é, na sua estrutura interna, bastante complexo e cheio de contradiçôes. Com efeito, temos duas alternativas que têm uma relação de heterogeneidade entre elas. Primeira: é certo ou é errado escolher tal pedra para determinado fim? Segunda: o fim posto é certo ou é errado? Vale dizer: uma pedra é realmente um instrumento adequado para esta finalidade? É fácil de ver que ambas as 
alternativas só podem desenvolver-se partindo de um sistema de reflexo da realidade (quer dizer, um sistema de atos que não-existem-em-si) que funciona dinamicamente e que é dinamicamente elaborado (LUKÁCS, 1981, p. 42).

O trabalho, como comportamento especificamente humano, é intencional e possui um propósito predeterminado, uma característica marcadamente cognitiva, justamente o que o distingue do comportamento instintivo de outros animais. É nesta predeterminação que apontamos a avaliaçáo como elemento intrínseco ao processo de trabalho, estando relacionada com o conhecimento objetivo da realidade e com a escolha entre as alternativas ${ }^{11}$ envolvidas, auxiliando a projetar e monitorar os resultados previamente ideados.

Nessa busca dos meios que objetivamente contribuirão para alcançar o fim posto se localiza, como atividade exclusivamente humana, o conhecimento objetivo do sistema causal tanto dos objetos quanto dos processos cuja realizaçáo pode levar a efetivar o fim teleologicamente posto. No entanto, segundo Lukács (1981, p. 26),

[...] a posiçáo do fim e a busca dos meios nada podem produzir de novo enquanto a realidade natural permanecer o que é em si mesma: um sistema de complexos cuja legalidade continua a operar com total indiferença com respeito a todas as aspirações e idéias do homem. Aqui a busca tem uma dupla função: de um lado evidenciar aquilo que em si mesmo governa os objetos em questáo independentemente de toda consciência; de outro lado descobrir neles aquelas novas conexôes, aquelas novas possíveis funçóes que, quando postas em movimento, tornam efetivável o fim teleológicamente posto.

As ações do ser social, diferentemente de todos os outros animais, são precedidas pelo "notável fenômeno da intencionalidade". Ao trabalhar o homem estabelece um telos, a partir de uma cognoscibilidade preexistente póe uma finalidade, o que o separa definitivamente e qualitativamente de todos os animais. De acordo com Bhaskar (1979, p. 44), 
A ação humana é caracterizada pelo notável fenômeno da intencionalidade. Tal fenômeno parece depender da característica de que as pessoas são coisas materiais dotadas de um certo grau de complexidade neurofisiológica que as possibilita, como os demais animais superiores, não apenas iniciar mudanças de maneira intencional, monitorar e controlar suas atuaçôes, mas também monitorar a monitoração de tais atuaçóes e serem capazes de comentá-las. Esta capacidade para monitoraçáo de segunda ordem torna possível também um comentário retrospectivo sobre as açóes, o que confere um estatuto especial à explicação da pessoa sobre seu próprio comportamento, fato que é reconhecido na melhor prática de todas as ciências psicológicas.

No ato isolado de trabalho, em que a intenção é a transformação da natureza visando a produção imediata de valores de uso, ${ }^{12} \mathrm{o}$ ato de avaliar é uma condição que diz respeito ao sujeito. Entretanto, nos momentos ulteriores desdobrados do trabalho, em que esta produção de valores de uso se dá por meio da ação de um homem, ou de um grupo específico de homens sobre outros homens afim de que estes realizem posiçóes teleológicas concretas, o ato de avaliar juntamente com o ato de trabalhar torna-se cada vez mais social. Porém, em ambos os casos há reflexo na prática dos sujeitos que são objetos da avaliação, tanto no processo que mais se aproxima da avaliação interna, como é o primeiro caso, quanto no mais próximo da avaliação externa, como no segundo.

Quando o ato de trabalhar, ou seja, o pôr teleológico, é realizado sob a direção de um homem, ou de um grupo específico de homens sobre a ação de outros homens afim de que estes últimos efetuem a transformação direta da natureza, ocorre o que Lukács denomina de posição teleológica secundária. Mas também nas posiçóes teleológicas secundárias o ato avaliativo é relevante para mais bem executar o ato de trabalho pretendido pelos homens, mesmo que nos reportemos a momentos que repousam na história do ser social, como nesse sugerido por Lukács (1981, p. 56):

Pensamos na caça no período paleolítico. As dimensôes, a força e a periculosidade dos animais a serem caçados tornam necessária a cooperação de um 
grupo de homens. Ora, para tornar essa cooperação funcional e eficaz, é preciso distribuir os participantes de acordo com as funçôes (batedores e caçadores). As posiçóes teleológicas que aqui se verificam têm, na realidade, um peso secundário em relação ao trabalho imediato; deve ter havido uma posição teleológica anterior que determinou o caráter, o papel, a função etc., das posiçóes singulares concretas e reais cujo objetivo é um objeto natural. Deste modo, o objeto dessa finalidade secundária já não é um elemento da natureza, mas a consciência de um grupo humano; a posição do fim já não visa a transformar diretamente um objeto natural, mas, em vez disso, a fazer surgir uma posição teleológica que tenha, porém, como objetivo alguns objetos naturais; da mesma maneira, os meios já não são intervenções imediatas sobre objetos naturais, mas pretendem provocar estas intervençôes por parte de outras pessoas.

Ainda que num estágio mais evoluído do processo de trabalho, com o incremento da divisão social do trabalho, haja uma predominância das posições teleológicas secundárias com relação às primárias, estas continuam sendo socialmente determinadas e refletindo na práxis social dos sujeitos envolvidos. É neste momento de determinação e caracterização da práxis social que ganha força decisiva a categoria do dever ser. Segundo Lukács (1981, p. 71), "Quando, então, observamos que o ato decisivo do sujeito é a própria posição teleológica e sua realização, fica imediatamente evidente que o momento categorial determinante destes atos implica o surgimento de uma práxis caracterizada pelo dever-ser".

O estabelecimento pelo trabalho da atitude de pôr um fim, pela própria característica de ser o trabalho a materialização de algo previamente ideado, traz como marca o fato de que o fim surja na consciência antes de sua efetivação, sendo que durante o processo os passos são determinados pela posição do fim. Segundo Lukács (1981, p. 71-72, grifo do autor):

Sob este aspecto, o significado da causalidade posta consiste no fato de que os anéis, as cadeias causais etc. são escolhidos, postos em movimento, abandonados ao seu próprio movimento, para 
favorecer a realização do fim estabelecido desde o início. Mesmo que no processo de trabalho, como diz Hegel, a natureza apenas "se consuma", mesmo este processo não é espontâneo, mas é guiado teleologicamente e o seu desenvolvimento consiste exatamente no aperfeiçoamento, na concretizaçáo e no diferenciamento desta orientaçâo teleológica dos processos espontâneos (o uso de forças naturais como fogo ou água para trabalhar). Do ponto de vista do sujeito, este agir determinado a partir de um futuro definido é exatamente um agir orientado pelo dever-ser do fim.

Podemos inferir a gênese ontológica do processo de avaliar como parte deste dever ser estabelecido pelo fim alcançado pelo ato de trabalho, porém, tal derivação não é direta e mecânica e os desdobramentos ulteriores do processo de avaliar guardam estreita conexão ontológica com esta forma originária do dever ser.

Segundo nossa compreensão a gênese ontológica da avaliação teria relevância neste momento, justamente no ato de pôr a causalidade, auxiliando no reconhecimento e ajuizamento e na escolha correta das relaçóes causais ou dos procedimentos adequados que possam efetivamente realizar o fim posto. Vale a pena ressaltar que o critério de correção tanto do conhecimento quanto da posição da causalidade é determinado pelo fim, ou seja, somente se o fim ideado se efetiva é que podem ser considerados válidos tanto a apreensão do reflexo correto da realidade, quanto dos meios utilizados para realizar a intencionalidade materializada pelo trabalho. Afirmamos ser inviável qualquer tentativa de hierarquizar a gênese ontológica do ato de avaliar neste processo, muito embora seja fundamental no reconhecimento de um "reflexo correto da realidade" que venha auxiliar na realização de um dado dever-ser, pois, para Lukács (1981, p. 72):

Naturalmente, o reflexo correto da realidade é a condição inevitável para que um dever-ser funcione de maneira correta; no entanto, esse reflexo correto só se torna efetivo quando conduz realmente à realização daquilo que deve-ser. Portanto, aqui não se trata simplesmente de um reflexo correto da realidade em geral, de reagir a ela de um modo geral adequado, 
ao contrário, a correção ou o erro, isto é, qualquer decisão que se refere a uma alternativa do processo de trabalho, só pode ser avaliada a partir do fim, de sua efetivação. Deste modo, aqui também temos uma insuprimível interaçáo entre dever-ser e reflexo da realidade (entre teleologia e causalidade posta), onde a função de momento predominante cabe ao dever-ser.

O pretenso tratamento do ato de avaliação na sua universalidade, juntamente com o fato de relacionar sua base ontológica ao dever ser, deve necessariamente considerar o estabelecimento do valor como critério da avaliação, pois, ainda segundo Lukács (1981, p. 79):

Indissoluvelmente ligado ao problema do dever-ser enquanto categoria do ser social está o problema do valor. Com efeito, uma vez que o dever-ser enquanto fator determinante da práxis subjetiva no processo de trabalho só pode cumprir esta função específica porque o que se pretende tem valor para o homem, então o valor não poderia tornar-se realidade neste processo se não fosse capaz de inserir no homem que trabalha o dever-ser de sua realização como critério da práxis.

No entanto, o dever-ser atua como regulador do processo de trabalho, ao passo que o valor interfere mais especificamente sobre a posição do fim, atuando como critério de avaliação da validade do produto realizado neste processo. Sendo assim, o valor significa a aprovação da posição teleológica correta ou, melhor dizendo, a correção da posição teleológica. Neste sentido, não há como dissociar julgamento e ajuizamento e tomada de decisão no processo avaliativo considerado na sua integralidade. Lukács (1981, p. 84) assinala que

[...] no que se refere à gênese ontológica do valor, devemos partir do fato de que, no trabalho como produção de valores de uso (bens), a alternativa do que é útil ou inútil para a satisfação das necessidades entra como um elemento ativo do ser social. Por isso, quando abordamos o problema da objetividade do valor, percebemos imediatamente que nele 
está contida uma aprovação da posição teleológica correta, ou, melhor dizendo: a correção da posiçáo teleológica - tendo como pressuposto sua atuação correta - significa que o respectivo valor foi realizado concretamente.

A gênese ontológica da avaliação está ligada à gênese ontológica do valor, pois nele está contida uma aprovação da posição teleológica correta, logo a avaliação em sua gênese está diretamente ligada à correção da posição teleológica, ressaltando seu caráter sócio-ontológico de "se ... então" com a satisfação da necessidade, o que também confere uma valoração ex-post 13 $^{3}$ da avaliação com relação ao ato de trabalho.

O sentido ontológico da avaliação no processo de constituição do ser social se deve ao fato da mesma se constituir como um momento do ser social que acontece mesmo quando este processo não é de todo consciente ao sujeito que o realiza. Ou seja, o ato de avaliar é imanente ao processo mediante o qual o homem se constrói e realiza sua história ao responder às alternativas concretas que lhe são apresentadas tanto na sua relação com a natureza quanto com outros homens. Embora não sendo o determinante principal tem papel fundamental na realização do valor como tal, justamente devido ao fato deste último ser uma relação entre fins e meios do sujeito que age. Nesta fundamentação ontológica do processo de avaliação nos referimos ao valor de uso como o que satisfaz uma dada necessidade humana, não se constituindo num empecilho a uma análise do valor num sentido mais avançado economicamente, pois consideramos o valor de uso como a insuprimível base real de uma forma mais avançada de valor, como é o caso do valor de troca.

Podemos afirmar que o ato de avaliar comparece de forma indissociável no valor, estando presente justamente no momento em que o valor se estabelece corretamente como tal, ou seja, no processo de valoração do valor, no momento decisivo de responder se determinado valor satisfaz ou não à necessidade que de certa forma o engendrou. Logo, a avaliação atua como elemento insuprimível da práxis social na resolução das alternativas do complexo concreto das possibilidades reais de reação prática a uma dada problematicidade do processo de formação de um dado valor, auxiliando a nortear as escolhas que realizam ou negam o valor. ${ }^{14}$ Logo a característica ontológica do ato de avaliar está insuprimivelmente ligada ao processo 
histórico social de respostas que culminam em valores. Este processo juntamente com o desenvolvimento social do ser que realiza valor adquire um nível de exemplaridade refletindo no agir humano-social, tornando-se parte do processo de reprodução social.

$\mathrm{O}$ ato de avaliar tem um papel crucial na sua característica teleológica ao responder corretamente às alternativas, sendo parte indissociável do homus economicus e diretamente ligado náo somente ao momento ontologicamente marcado pelo fato social da superação momentânea de uma necessidade, mas à preocupação com a manutenção do homem como espécie, sua reprodução e manutenção posterior. Assim sendo, a avaliação é parte do processo de mudança e conservação que caracteriza a reprodução e construção social da espécie humana. Sendo uma ação deliberada por atos mais ou menos conscientes, estritamente ligada a uma alternativa social, a avaliação sofre, como a sociedade que lhe empresta sentido, ininterruptas mudanças de acordo com as necessidades sociais de cada época histórica. Porém, indiferentemente do estágio em que se encontrem tais processos sociais, as mudanças por eles sofridas não alteram a substancialidade ${ }^{15}$ presente no ato de avaliar. Parte dessa substancialidade e o que lhe dá essencialidade social é o fato de auxiliar no processo de negação ou afirmação de determinadas alternativas que agem positiva ou negativamente afirmando ou negando um determinado valor como tal, processo este denominado, com base em Luckesi (1995), de ajuizamento.

Vale a pena ressaltar a primazia ontológica das necessidades sociais de cada época como balizadoras da avaliação. Logo, o nexo social do processo de avaliar é determinado pelas necessidades sociais de cada época. Se os interesses sociais de cada época se distinguem chegando a uma declarada oposiçáo, tal característica é transferida para o processo de avaliação demarcando, de acordo com sua função social, a direção de sua eficácia ou ineficácia como processo social. Consideramos este fato essencial ao nos reportarmos à avaliação assentada na meritocracia, realizada nos moldes do capitalismo.

O processo de avaliação é constituído de posições alternativas teleológicas sendo que, para Lukács (1981, p. 98):

O valor destas posiçôes é decidido por sua verdadeira intenção, tornada objetiva na práxis, intenção que pode orientar-se para o essencial ou para o 
contingente, para aquilo que leva para diante ou que freia etc. Do mesmo modo que no ser social, todas estas tendências estão presentes e realmente ativas, e dado que, por isso, elas produzem, no homem que age, alternativas em diversas direçóes, em diversos níveis etc., [...]. Com efeito, a alternativa de uma determinada práxis, não está somente em dizer 'sim' ou "não" a um determinado valor, mas também na escolha do valor que forma a base da alternativa concreta e nos motivos pelos quais se assume esta posição.

Como consideramos o desenvolvimento econômico determinante em última instância da práxis social, os valores que se afirmam ou se negam se referem necessariamente ao embate das classes essenciais em torno desse desenvolvimento, sofrendo ou empreendendo as pressões daí advindas. Deste modo, a intenção de um determinado processo de avaliação sendo referente a um dado desenvolvimento econômico e social está ligada à sua negação e contestação ou afirmação e legitimação.

\section{Considerações finais}

Ao nos reportarmos para o desenvolvimento do modo de produçáo capitalista, no seu atual estágio de configuração, veremos que por mais que este tenha se alterado na sua relação com a esfera da produção, dada a intensificação produtiva atual, recrudesce a contradição fundamental que compóe o cerne deste modo de produzir a vida. Talvez uma das características mais marcantes seja que simultaneamente à produçáo de riquezas em escala global ${ }^{16}$ aumenta o número de seres humanos vivendo em condições de pobreza. O que existe no mundo moderno é uma imensa desigualdade planetária. Para Ramonet (1998, p. 155), vivemos em

[...] um planeta onde as desigualdades se aprofundam e onde, entre 5 bilhóes de habitantes, apenas 500 milhóes vivem confortavelmente, enquanto 4,5 bilhôes estão privados do necessário. Um planeta onde a fortuna das 358 pessoas mais ricas, bilionários em dólares, é superior à renda anual dos $45 \%$ de habitantes mais pobres, ou seja, 2,6 bilhóes de pessoas. 
Como não poderia deixar de ser, a eliminação desse quadro não figura entre as possibilidades dessa forma de produzir a vida, por mais que o discurso de seus apologetas de plantão ideologicamente tente transparecer o contrário. Chega-se a um paradoxo: o sistema regido pelo capital não pode eliminar a pobreza, deve mantê-la em níveis suportáveis, para si, de barbarização, pois se trata de um mal necessário e vital para o sistema de produçáo capitalista. Faz parte da ontologia do modo de produção capitalista manter parte substantiva dos seres humanos vivendo em condiçóes de barbárie "controlada". Inúmeros artifícios ideológicos são lançados para obliterar tal situação, dentre os quais figura a aposta na educação eficiente como condição suprema para reverter o irreversível quadro de pobreza mundial dentro da lógica capitalista.

Trata-se de fazer crer na idéia de que a condição de pobreza, descolada das relaçóes sociais que a engendra, diz respeito ao próprio nível de ineficiência dos pobres. Dito de outro modo, os pobres do mundo dotados de um espírito empreendedor podem, por meio de atitudes eficientes, superar sua condição de pobreza. Nesse discurso, a educação eficiente se mostra como condição sine qua non de reversão do grau de pobreza. Para que isso seja efetivável, a educação deve ser atacada na alardeada falta de eficiência que historicamente a caracterizaria.

A suposta avaliação que se faz da educação, por meio de instrumentos de testagem em larga escala, executa um forte papel de justificativa para a existência da pobreza, ou seja, enquanto persistirem os maus resultados escolares o enorme contingente que vive na pobreza não tem possibilidade de reverter essa condição. É este o movimento que tentamos compreender, isto é, o movimento que caracteriza a educação eficiente nos seus resultados como estratégia primordial para o alívio da pobreza. Afirmamos que subjacente a qualquer construção social há uma ontologia que a embasa e a formata; isso se aplica à construçáo estratégica do papel da educação frente à pobreza efetuada por organismos internacionais, sobretudo pelo Banco Mundial.

\section{Notas}

1 De acordo com Carrara (2002, p. 1), "Flui admirável verborragia prescritiva dos textos que pretendem esgotar a descrição de atividades e funçôes pertinentes à avaliação da aprendizagem escolar. Medir, 
especificar, localizar, integrar, analisar, definir, examinar, selecionar, verificar, formular, identificar, construir, estabelecer, dominar, interpretar e observar constituem asserçóes verbais típicas do exemplário básico pertinente ao esforço de retratar, através de ações finais do avaliador e do educando, o que, na verdade, constitui processo permeado de eventos transversais diversos e complexos”.

2 Denominamos processo de avaliação geral aquele que compreende e extrapola os demais campos particulares de avaliação, como é o caso da avaliação escolar.

3 Essa expressão é utilizada por Luckesi (1995, p. 69) que esclarece: "Em lógica, juízos são afirmaçóes ou negaçóes sobre alguma coisa. Essas afirmações ou negações poderão incidir sobre o aspecto substantivo ou sobre o aspecto adjetivo da realidade. $\mathrm{O}$ juízo que se faz sobre o aspecto substantivo da realidade recebe a denominação de juizo de existência, na medida em que sua expressão pode ser justificada pelos dados empíricos da realidade. O juízo, porém, que expressa a qualidade do objeto que está sendo ajuizado, recebe a denominação de juízo de qualidade, desde que incida sobre uma realidade atribuída ao objeto. O primeiro pretende dizer o que o objeto é; o segundo tem por objetivo expressar uma qualidade que se atribui a um objeto. Enquanto o juízo de existência é produzido numa relação direta do sujeito com o objeto, o juízo de qualidade é produzido por um processo comparativo entre o objeto que está sendo ajuizado e um determinado padrão ideal de julgamento."

4 A categoria reflexo será usada no decorrer deste texto amparada na ontologia lukácsiana. Na passagem que segue Lukács (1981, p. 36) assim explicita sua perspectiva: "Neste capítulo e nos sucessivos, voltaremos mais vezes a referir-nos aos modos concretos de manifestar-se e de se exprimir da consciência, bem como ao concreto modo de ser de sua natureza não mais epifenomênica. Aqui só podemos fazer alusão - e neste momento de modo inteiramente abstrato - ao problema de fundo. Temos aqui a indissociável solidariedade de dois atos que são, em si, mutuamente heterogêneos, os quais, porém, nesta nova relação ontológica, constituem o verdadeiro complexo real do trabalho e, como veremos, perfazem o fundamento ontológico da práxis social, e até do ser social no seu conjunto. Os dois atos heterogêneos a que nos referimos são: de um lado, o reflexo 
mais exato possível da realidade considerada e, de outro lado, o correlato por aquelas cadeias causais que, como sabemos, são indispensáveis para efetivar a posição teleológica. Esta primeira descrição do fenômeno irá mostrar que dois modos de considerar a realidade que são heterogêneos entre si formam a base da especificidade ontológica do ser social, ambos cada um por si mesmo e na combinação indispensável dos dois. Se iniciarmos agora a nossa análise com a reflexão, isto imediatamente mostra uma demarcaçáo precisa entre objetos que existem independentemente do sujeito, e sujeitos que delineiam estes objetos com um grau maior ou menor de aproximação, por atos de consciência, para apropriar-se deles espiritualmente. Essa separação tornada consciente entre sujeito e objeto é um produto necessário do processo de trabalho e com isso a base para o modo de existência especificamente humano. Se o sujeito, enquanto separado na consciência do mundo objetivo, não fosse capaz de observar e de reproduzir no seu ser-em-si este último, jamais aquela posição do fim, que é o fundamento do trabalho, mesmo do mais primitivo, poderia realizar-se.

5 Entendemos que essa supressão da situação ou do objeto avaliado significa um estacionamento no processo de juizo de valor detendo-se este nos aspectos emanados do juízo de existência. Tal juízo, por si, pode nos deixar indiferentes, uma vez que expressa apenas o que o objeto é, ao passo que o juízo de qualidade implica numa tomada de decisão manifestada/revelada numa atitude de não indiferença frente ao objeto, ação ou situação avaliada.

6 Essa diferenciação se dá até mesmo por superação; mesmo que o ato avaliativo possa comportar o ato de verificação, este último é ultrapassado em qualidade pelo primeiro.

7 A distinção entre avaliação interna e externa advém do campo de avaliação de projetos sociais relacionado à função de quem realiza a avaliação e, segundo Cohen e Franco (1993, p. 111), "É possível distinguir quatro tipos de avaliaçáo, considerando o agente que a realiza. Para começar podem ser diferenciadas segundo a participação ou não do avaliador na equipe executora do projeto. Outra forma é a que procura combinar os dois tipos de pessoas e a última é a denominada participativa, que incorpora os beneficiários." 
8 O Fundo de Manutenção e Desenvolvimento do Ensino Fundamental e de Valorização do Magistério (BRASIL, 1997) substituído no governo de Luiz Inácio Lula da Silva pelo Fundo de Manutenção e Desenvolvimento da Educação Básica e de Valorização dos Profissionais da Educação (BRASIL, 2007). Embora o segundo amplie a cobertura de sua ação, ambos se constituem em mecanismos que não agregam novos valores ao investimento em educação, operam, ao contrário na redistribuição de recursos já vinculados à educação.

9 Nossa concepção de história está embasada em Marx e para compreender a concepção de história em Marx, segundo Moraes (2000, p. 20): "Em primeiro lugar, é preciso destacar a concepção de história de Marx, de forte inspiração hegeliana. Se não encontramos em sua obra uma filosofia da história expressamente discutida e elaborada, é possível, porém, dela depreender sua compreensão da história como solo ontológico, como horizonte de inteligibilidade do ser. A história é, para Marx, a forja do especificamente humano mediante o trabalho, o devir da natureza para o homem”.

10 Moraes (2000, p. 26) ao referir-se a concepção do trabalho em Marx, esclarece que: "O trabalho é a forma por excelência do encontro entre sujeito e objeto, possibilidade radical de conhecimento."

11 Usamos a categoria alternativa em consonância com a teoria Lukácsiana para a qual "A passagem do reflexo, como forma particular do não-ser ao ser, ativo e produtivo, do pôr nexos causais, apresenta uma forma desenvolvida da dynamis aristotélica, que pode ser considerada como caráter alternativo de qualquer pôr no processo de trabalho. Esse caráter aparece, em primeiro lugar, na posição do fim do trabalho. E pode ser visto com a máxima evidência também examinando atos de trabalho muito primordiais. Quando o homem primitivo escolhe, de um conjunto de pedras, uma que lhe parece mais apropriada aos seus fins e deixa outras de lado, é óbvio que se trata de uma escolha, de uma alternativa. E no exato sentido de que a pedra, enquanto objeto em-si-existente da natureza inorgânica, não estava, de modo nenhum, direcionada, em sua forma, a tornar-se instrumento deste pôr. Também é óbvio que a grama não cresce para ser comida pelos bezerros e estes não engordam para fornecer a carne que alimenta os 
animais ferozes. Em ambos os casos, porém, o animal que come está ligado biologicamente ao respectivo tipo de alimentação e esta ligação determina a sua conduta de forma biologicamente necessária. Por isso mesmo, aqui a consciência do animal está determinada num sentido unívoco: é um epifenômeno, jamais será uma alternativa. Ao contrário, a escolha da pedra como instrumento é um ato de consciência que não tem mais caráter biológico [...]. Mas é também fácil de ver que só quando os resultados do reflexo não-existente se solidificam numa práxis estruturada em termos de alternativa é que pode provir do ser natural algo que exista no quadro do ser social, por exemplo, uma faca ou um machado, isto é, uma forma de objetividade do que existe total e radicalmente nova. Com efeito, a pedra, no seu ser-em-si e no seu ser-assim natural nada tem a ver com a faca ou o machado. Esse traço peculiar, da alternativa, aparece ainda mais plasticamente num nível um pouco mais evoluído, isto é, não só quando a pedra é escolhida e usada como instrumento, mas, em vez disto, para que se torne mais adequada para o trabalho, é submetida a um novo processo de elaboração. Neste caso, quando o trabalho é realizado num sentido ainda mais próprio, a alternativa revela ainda mais claramente a sua verdadeira essência: não se trata apenas de um único ato de decisão, mas de um processo, uma ininterrupta cadeia temporal de alternativas sempre novas. Não se pode deixar de perceber, quando se reflete, ainda que rapidamente sobre qualquer processo de trabalho - mesmo o mais primitivo - que nunca se trata simplesmente da execução mecânica de uma finalidade. A cadeia causal na natureza se realiza 'por si', de acordo com a sua própria necessidade natural interna do 'se ... então'. No trabalho, ao contrário, como já vimos, não só o fim é teleologicamente posto, mas também a cadeia causal que o realiza deve transformar-se em uma causalidade posta. Com efeito, tanto o meio como o objeto, em si mesmos, são coisas naturais sujeitas à causalidade natural e somente na posição teleológica, somente por esta forma, poderão receber o pôr da existência social no processo de trabalho, embora permaneçam ainda objetos naturais. Por esta razáo, a alternativa é continuamente repetida nos detalhes do processo de trabalho. Cada movimento individual no processo de afiar, triturar etc. deve ser considerado corretamente (isto é, deve ser baseada em um 
reflexo correto da realidade), ser corretamente orientado ao objetivo posto, corretamente levado a cabo pela mão etc. Se isso não ocorrer, então a causalidade posta deixará de operar a cada momento e a pedra voltará à sua condição de simples objeto natural, sujeito a causalidades naturais, nada mais tendo em comum com os objetos e os instrumentos de trabalho. Deste modo, a alternativa se amplia até ser a alternativa de uma atividade certa ou errada, de modo a dar origem a categorias que somente se tornam formas da realidade no processo de trabalho" (LUKÁCS, 1981, p. 42-43).

12 Neste caso temos o que Lukács (1981) denomina de posição teleológica primária.

13 As afirmaçóes de Cohen e Franco (1993, p. 108), mesmo que referidas à avaliação de projetos sociais, são de grande valia para caracterizar a avaliação ex-post: "Na construção de tipologias de avaliação é possível distinguir as tradiçóes de diferentes disciplinas (sociologia, educação etc.). Quando as raízes se encontram na economia, a distinção clássica é entre avaliação ex-ante e ex-post. A primeira é realizada ao começar o projeto, antecipando fatores considerados no processo decisório. A segunda ocorre quando o projeto já está em execução ou já está concluído e as decisóes são adotadas tendo como base os resultados efetivamente alcançados".

14 Para efeito de exemplo, retomemos o exemplo de Lukács (1981) e imaginemos a situação de trabalho antes descrita, quando para a realização de um determinado pôr teleológico o sujeito deva escolher uma determinada pedra dentre outras, a fim de transformar a natureza e com isso satisfazer uma determinada necessidade sua ou de sua espécie. Pois bem, o ato de trabalho sendo uma atividade previamente ideada requer cognoscibilidade e reflexão, pois várias pedras podem ser tomadas na tentativa de transformar a realidade. Ao se voltar para cada pedra o sujeito percebe essa relação como uma relação prenhe de alternativas, algumas pedras podem não servir para a transformação almejada, devido a características que o sujeito, no ato de trabalho, deve reconhecer, outras podem servir, mas de forma menos eficiente. Logo, a resposta correta ao complexo concreto de possibilidades, neste caso formado pelas variadas pedras, se materializa pela escolha da pedra que melhor desempenhe a 
função que aquela necessidade requer ou que realize e afirme o seu valor de uso. Lembre-se que esse acontecimento é histórico e social, portanto pode ser cumulativo.

15 Entende-se por substância "[...] aquilo que na contínua mudança das coisas, mudando ela mesma, pode conservar-se na continuidade delas. No entanto, este dinâmico conservar-se não está necessariamente ligado a uma 'eternidade'; as substâncias podem surgir e perecer, sem que com isto, desde que se mantenham dinamicamente durante o tempo da sua existência, deixem de ser substâncias" (LUCKÁCS, 1981, p. 45).

16 Aguiar e Araújo (2003, p. 22), na obra de título sugestivo, Bolsa-escola: educaçáo para enfrentar a pobreza, ilustram bem este fato da seguinte forma: "Contudo, o que se observou no mundo contemporâneo é que o crescimento econômico por si não distribui a riqueza, seja nacional ou mundial, a todos os segmentos da sociedade. Evidentemente, o mundo de hoje é mais confortável, a produção de alimentos com a intensa mecanização cresceu assustadoramente, os bens tornaram os lares pequenas fábricas produzindo bem estar jamais visto pela História. Por outro lado, milhóes de habitantes espalhados pelo mundo, desenvolvido e não-desenvolvido, vivem como habitantes medievais do ponto de vista do consumo. O binômio pobreza e desigualdade determina as disfunções".

\section{REFERÊNCIAS}

AGUIAR, M.; ARAÚJO, C. H. Bolsa-escola: educação para enfrentar a pobreza. Brasília: UNESCO, 2003.

BHASKAR, R. The possibility of naturalism. Brighton: Harvest, 1979.

BRASIL. Decreto no 6.253, de 13 de novembro de 2007. Dispóe sobre o Fundo de Manutenção e Desenvolvimento da Educação Básica e de Valorização dos Profissionais da Educação (FUNDEB), regulamenta a Lei no 11.494 , de 20 de junho de 2007, e dá outras providências. Diário Oficial da União, Brasília, p. 18, 14 nov. 2007. Disponível em: <http:// www.planalto.gov.br/ccivil_03/_ato2007-2010/2007/Decreto/D6253. htm>. Acesso em: 15 fev. 2011. 
BRASIL. Lei ํㅜ 9.394, de 20 de dezembro de 1996. Estabelece as diretrizes e bases da educação nacional. Diário Oficial da União, Brasília, p. 27833, 23 dez. 1996. Disponível em: <https:/www.planalto.gov.br/ ccivil_03/Leis/L9394.htm>. Acesso em: 10 jan. 2011.

BRASIL. Ministério da Educação e Cultura. Resolução CNE/CEB n. 3, de 8 de outubro de 1997. Fixa Diretrizes para os Novos Planos de Carreira e de Remuneração para o Magistério dos Estados, do Distrito Federal e dos Municípios. Brasília: MEC, 1997.

CARRARA, K.; RAPHAEL, H. S. Apresentação. In. CARRARA, K.; RAPHAEL, H. S. (Org.). Avaliação sob exame. Campinas, SP: Autores Associados, 2002.

COHEN, E.; FRANCO, R. Avaliação de projetos sociais. Petrópolis, RJ: Vozes, 1993.

LUCKESI, C. C. Avaliação da aprendizagem escolar. São Paulo, Cortez, 1995.

LUKACS, G. Per l'ontologia dell 'essere socile II. Roma: Riuniti, 1981.

MARX, K. O Capital: crítica da economia política. São Paulo: Nova Cultural, 1988. v. 1.

MEDEIROS, J. L. A economia contra o horror econômico. 2004. 204 pgs. Tese (Doutorado em Economia) - Departamento de Economia, Universidade Federal do Rio de Janeiro, Rio de Janeiro, 2004.

MORAES, M. C. M. de. Reformas de ensino, modernização administrada: a experiência de Francisco Campos: anos vinte e trinta. Florianópolis: NUP/UFSC, 2000.

NAGEL, L. H. Avaliação, sociedade e escola: fundamentos para reflexão. Curitiba, PR. Secretaria de Estado da Educação, 1996.

RAMONET, I. Geopolitica do caos. Petrópolis, RJ: Vozes, 1998.

SAUL, A. M. A avaliação educacional. Idéias, São Paulo, n. 22, p. 61-68, 1994. 


\section{Ontology of the evaluating La ontología del acto de act evaluación}

\section{Abstract}

This article problematizes the educational results presented either by national or by international instruments of evaluation, which refer to an alleged anachronism of the school. With the publication of these results, it comes to the surface the statement about the inefficiency of the school in assuring satisfactory conditions of teaching and learning of the subjects, attitudes and abilities that are known as necessary to a satisfactory society development. The article incorporates the ontological assumptions that base this process of "change in permanence", that involves the reforms of the State's system, with the imposition of the appraiser State, and the recrudescent relevance of the educational evaluation mechanisms in wide scale, mainly from 1990 on. We discuss the ontological assumptions of the evaluation process as work constituent, as well as the ontological characterization attributed to these processes by the dominant class, concluding that they are characterizations of distinct intentionalities, which is lead to distinct projects, and, therefore, have in mind distinct models of men.

Keywords: Educational evaluation. Brazilian Basic education. Ontology.

\section{Resumen}

En este artículo se discute los resultados educacionales presentados $\mathrm{o}$ por instrumentos nacionales de evaluación, o por internacionales, los cuales sujetan a un supuesto anacronismo de la escuela. De una manera agregada a la promoción de esos resultados sobresale la afirmación acerca de la ineficiencia de la escuela en garantizar condiciones satisfactorias de enseñanza y aprendizaje de contenidos, actitudes y destrezas tenidas como necesarias al buen funcionamiento de la sociedad. Para analizar dicha situación, busca entender presupuestos ontológicos que basan este proceso de "cambios en la estadía" que incluye las reformas del aparato del Estado, con imposición del Estado evaluador, y el recrudecimiento de la relevancia de los mecanismos de evaluación educacional en ancha escala, sobretodo a partir de 1990. Discutimos los presupuestos ontológicos del proceso de evaluación como constituyentes del trabajo, así como la caracterización ontológica asignada a estos procesos por la clase dominante, concluyendo que se tratan de caracterizaciones de intencionalidades distintas, parten de proyectos sociales distintos, y, por lo tanto, atienden modelos de hombres distintos.

Palabras clave: Evaluación educacional. Educación Básica brasilera. Ontología. 
João Batista Zanardini

E-mail: j.zanardini@uol.com.br

Recebido em: 18/12/2010

Versáo final recebida em: 8/3/2011

Aprovado em: 10/4/2011 